\title{
Los sambenitillos. Imagen y penitencia en el mundo hispánico (siglos XVI-XVIII)
}

The Sambenitillos. Image and Penancein the Hispanic World (XVI-XVIIIth Centuries)

Les sambenitillos. Image et pénitence dans le monde hispanique (XVIe-XVIIIe siècles)

Manuel Peña Díaz

\section{OpenEdition}

\section{Journals}

Edición electrónica

URL: http://journals.openedition.org/rhj/7522

DOI: $10.4000 /$ rhj.7522

ISSN: 0719-4153

Editor

ACTO Editores Ltda

Referencia electrónica

Manuel Peña Díaz, «Los sambenitillos. Imagen y penitencia en el mundo hispánico (siglos XVI-XVIII) », Revista Historia y Justicia [En línea], 15 | 2020, Publicado el 30 noviembre 2020, consultado el 02 diciembre 2020. URL : http://journals.openedition.org/rhj/7522 ; DOI : https://doi.org/10.4000/rhj. 7522

Este documento fue generado automáticamente el 2 diciembre 2020

Revista Historia y Justicia 


\section{Los sambenitillos. Imagen y penitencia en el mundo hispánico (siglos XVI-XVIII)}

The Sambenitillos. Image and Penancein the Hispanic World (XVI-XVIIIth Centuries)

Les sambenitillos. Image et pénitence dans le monde hispanique (XVIe-XVIIIe siècles)

Manuel Peña Díaz

\section{NOTA DEL EDITOR}

Recibido : 15 de mayo de 2020 / Aceptado: 07 de octubre de 2020

1 El 5 de mayo de 1490 el Inquisidor General, Tomás de Torquemada, mandó una carta acordada a los tribunales en la que daba cuenta de la forma y el modo que los condenados debían llevar la mácula cotidiana a la que habían sido sentenciados:

Que los reconciliados traigan toda su vida un sambenitillo de color negro o pardillo de paño de la tierra, de dos palmos en largo y uno en ancho, con dos cruces, una detrás y otra delante, coloradas, de palmo y medio de largo, y de través de un palmo $\mathrm{y}$ tres dedos en ancho, el cual han de traer sobre sus vestiduras ${ }^{1}$.

Esta prenda no era la misma que el hábito -más o menos largo- que los condenados tenían que portar en los autos de fe, ni siquiera tenía el tamaño de aquél adaptado para ser expuesto en las paredes de las iglesias. Los sambenitillos eran unos escapularios suficientemente grandes para llamar la atención de cualquier vecino que topase con alguno por la calle. ¿Cómo reaccionaron los condenados ante la obligación de llevar esta ropa de ignominiadurante un periodo determinado? ¿La cotidianeidad de su presencia en los espacios públicos lo fue por habitual o por la expectación que suponía encontrarse con individuos sambenitados? 


\section{La función simbólica: un debate abierto}

La memoria de la infamia, según Bartolomé Bennassar, fue una de las verdaderas razones del miedo a la Inquisición ${ }^{2}$. En primer lugar, esta infamia se registraba en el recuerdo colectivo. Según escribió Jaime Contreras:

aquella vestimenta obligatoria recordaba permanentemente el pasado herético del penitente o reconciliado. Porque ya no sólo se le privaba del estímulo social que comportaban los trabajos y vestidos de la época, sino que quedaba reducido y vencido por los agentes de la fe ${ }^{3}$.

4 Además, ese recuerdo generaba conflictos sociales y "contravenía las normas de la piedad y la caridad cristianas"4. En segundo término, la obligación de llevarlo por el período de tiempo asignado se aplicaba a los convictos de herejía y reconciliados (judaizantes, islamizantes o protestantes), pero siempre hubo excepciones, tanto en el uso de la imposición como en la preferencia de las víctimas. En tercer lugar, el sambenitillo era un cartel propagandístico del Santo oficio, de su capacidad de represión y de su poder coactivo ${ }^{5}$. Para José Carlos del Ama, el icono de los sambenitados estaba constantemente en la conciencia pública de la sociedad hispánica. Este historiador considera que la relevancia visual de esta vestimenta formaba parte de una serie de símbolos inquisitoriales con los que se expresaba "todo un sentir popular", es decir, formaba parte de un estado de opinión que se apropió y proyectó este ropaje como signo de infamia. No existe, desde su punto de vista, una imposición de arriba abajo, sino una constante reelaboración de elementos simbólicos que definen al grupo hegemónico, el de los cristianos viejos. Esa misma habilidad para crear y la enorme capacidad de reinvención explicaría el cambio de las cruces en los sambenitillos, ordenado por el cardenal Cisneros el 10 de julio de 1514, "en atención a que a la cruz se le hacían muchas irreverencias, sirviendo aquellas insignias frecuentemente de burla y

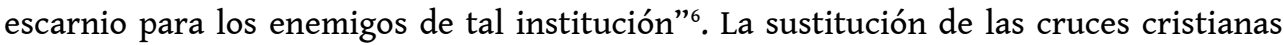
por las de aspa tuvo una función simbólica que se relaciona con la confesión y la reconciliación con la religión católica: El apóstol San Andrés confesó en esa cruz el ser verdad que Jesucristo era el hijo de Dios padre. Así los condenados señalados con el aspa en el escapulario eran reintegrados en la comunidad de católicos. Sin embargo, como recuerda Del Ama, lo que se compartía como un símbolo de reconciliación se proyectaba también como lo contrario, el sambenito "es el testimonio de la infamia de un individuo de su muerte social"?.

5 La función de esta vestimenta tendría la misma que la del estigma, en el sentido propuesto por Goffman: “un atributo profundamente desacreditador". En su análisis, el sociólogo canadiense planteaba un aspecto clave también para comprender la proyección de esta prenda: el lenguaje de relaciones que envuelve y hace suyo al atributo. Se trataría de conocer la ideología que explicaría la inferioridad del individuo y quedaría "cuenta del peligro que representa esa persona, racionalizando a veces una animosidad que se basa en otras diferencias"8. Esta teoría del estigma también propone reconstruir el lenguaje que se instala en las relaciones mediante la conceptualización del estigma, a lo que se añadiría el uso cotidiano de los términos que lo dotan de sentido y visibilidad.

6 La estigmatización sería un proceso infamante de vergüenza pública al que se vería sometido un individuo, que pasaría de ser "desacreditable" a "desacreditado". Como 
apunta Goffman, mediante la estigmatización es también otro individuo el que acaba llevando a cabo la función de la policía. Situación similar se produjo con los sambenitados a quienes, subraya Del Ama, "la parte más importante de la pena era ejecutada diariamente por el mismo pueblo. Cada vecino perfectamente integrado contribuía al ostracismo de los condenados". Se podría deducir, como hace este historiador, que la reconciliación con la Iglesia católica del sambenitado era una ficción por la muerte civil del condenado, no sólo por persecución popular sino también por la exclusión para alcanzar honores u ocupar oficios en la administración. Para constatar que esa ficción se producía, habría que distinguir entre el discurso religioso y la práctica cotidiana, del mismo modo que hay que diferenciar entre la representación del atributo y el lenguaje de las relaciones. En ese sentido, Del Ama plantea que el sambenito fue "una manifestación concreta del poder, siempre fluctuante", y en la vida cotidiana el sambenito era un icono de excepcionalidad y de normalidad, en tanto que representaba una institución como el Santo Oficio y un nexo simbólico entre la institución y el pueblo común 9 .

7 El miedo a la infamia existió. Sin embargo, sería erróneo determinar todos los comportamientos de los individuos por el riesgo a ser estigmatizados. Werner Thomas no considera que la tesis de Bennassar sobre la pedagogía del miedo a la Inquisición es matizable, y plantea que para comprender el funcionamiento del Santo oficio es necesario comprender que el control social fue tan vertical como horizontal, y es ahí, entre las corporaciones y colectivos, donde se encuentra una parte del "pueblo" o de la sociedad que actuó como instrumento de control social con tanta fuerza como los inquisidores. Admite que la tesis del miedo "tiene indudablemente validez en el caso de los extranjeros y de los grupos heterodoxos en España, tanto protestantes como judeoconversos, moriscos y otros. Sin embargo, es cuestionable si resulta aplicable a la totalidad de la sociedad española". Atribuye al historiador francés una visión dicotómica de la sociedad con dos polos opuestos: la Inquisición y los poderosos frente a la población atemorizada: "El concepto que Bennassar ofrece de la sociedad Ibérica como una sociedad de disenso, en la que algunos grupos elitistas estaban de acuerdo con la actuación inquisitorial y la población general no, es en mi opinión erróneo". Sugiere que la pedagogía inquisitorial no tuvo éxito por haber sido impuesta, sino porque existió "un modelo de consenso y de conformismo religioso que favorecía e inspiraba a la acción inquisitorial". En cierto modo, volvemos a la clásica tesis de la España racista cuyo fruto es la Inquisición que, a su vez,

reforzaba la necesidad de conformismo entre los españoles. Fue esta necesidad el motor del sistema de control social que debía vigilar la heterodoxia, y no el sentimiento de miedo entre la gente. Un conformismo, bien entendido, que tenía sus orígenes en la sociedad pre-inquisitorial y que no fue creado por el Santo Oficio $^{10}$.

8 Thomas considera que la exitosa y frecuente imposición del sambenito a los reconciliados fue una magnífica técnica de control social, en manos de autoridades competentes y de los mismos vecinos:

La estigmatización del reo mediante el sambenito facilitaba la vigilancia de su vida religiosa pública tanto por las instancias inquisitoriales como por el pueblo común, y esto en cualquier momento del día pues todos los reos estaban obligados a ponérselo siempre que saliera de su casa. Cada infracción se castigaba duramente con multas o azotes ${ }^{11}$. 
Incluso afirma que los sambenitillos limitaban la libertad de movimiento del condenado, porque "al mudarse el reo a otra ciudad o al viajar por el país, todo el mundo sabía leer sin problemas el libro de su pasado que era aquel hábito penitencial" ${ }^{12}$. Cabe preguntarse si el conformismo estaba tan asumido entre los cristianos viejos como entre los nuevos, si no hubo transgresiones $\mathrm{u}$ otro tipo de resistencia que obligaran a matizar la aplicación práctica de la teoría del control social. No en vano, Thomas también ofrece significativos y numerosos ejemplos sobre estos obstinados comportamientos que ponen en duda ambos modelos, el suyo y el de Bennassar.

\section{Orígenes y usos}

El origen de este escapulario pequeño se relacionaba con los vestidos (sacos y cilicios) que la Iglesia antigua y medieval imponía en las penitencias a sus fieles. Fray Antonio de Yepes aseguraba que la obligación de llevar durante la penitencia el sambenito mientras se estaba recluido se remontaba al Concilio Agatense de 506:

Y aunque algunos probaban bien y lloraban sus pecados, otros en acabándose el año de la penitencia como quedaban libres se volvían como el perro al vómito, y se enredaban con nuevos pecados, por lo cual fue necesario proveer de remedio, así el derecho civil como el canónico, y mandaron ambos derechos que en algunos pecados muy graves, públicos y escandalosos se recluyesen los penitentes en los monasterios (...) Esta vestidura pues que mudaban los penitentes, ahora la vistiesen fuera del monasterio, ahora dentro de él, la echaban ciertas bendiciones y se llamaba saco benedicto ${ }^{13}$.

11 Y proponía un origen bélico al sambenito callejero. Yepes relataba los vestidos que se ponían los monjes de las distintas órdenes militares en época medieval cuando iban a la guerra,

(...) pero por no se descuidar de su profesión, llevaban un escapulario pequeño, semejante al que nosotros usamos al tiempo del ir a dormir, el cual ellos llamaban sambenitillo (...) Este modo de decir me parece más probable y más conforme los derechos y a la costumbre antigua de España de dar los nombres de las personas a los vestidos de ellas, y al estilo de hablar nacido de las órdenes militares que a sus escapularios pequeños llamaban sambenitillos ${ }^{14}$.

12 En un informe de 1791, elaborado a petición de la Suprema, los inquisidores de Valladolid Manuel Gómez de Salazar y Antonio María de Galarza, situaban el origen de los sambenitos callejeros en

las disposiciones del Concilio Tarraconense de 1242, celebrado con asistencia del celoso San Raimundo de Peñafort, el cual en la forma de las penitencias de los reos de fe convertidos de su falsa creencia, ordena entre otras cosas que deban llevar dos cruces perpetuamente delante del pecho de color diferente del de los vestidos, de manera que puedan conocerse los que hacen solemne penitencia por los errores, en que hubiesen incurrido (...) de manera que se pusiese el hábito sobre los demás vestidos, con el fin de que los penitenciados fuesen reconocidos más patentemente por cualquiera parte, que se ofreciesen a la vista de las gentes ${ }^{15}$.

13 Era una práctica muy habitual que los sentenciados a reconciliación en España y en Italia, como señalaba el jurista Carena, fueran condenados "más a cárcel y hábito, y que el dicho hábito lo traiga públicamente encima de sus vestiduras"16. En las Instrucciones de Valdés de 1561 se hacía referencia a esta prenda durante la estancia del condenado en la cárcel perpetua: 
41. Si el reo estuviere confitente y su confesión fuere con las calidades que de Derecho se requieren, los Inquisidores, Ordinario y consultores, lo recibirán a reconciliación, con confiscación de bienes en la forma de Derecho, con hábito penitencial, que es un sambenito de lienzo o paño amarillo con dos aspas coloradas y la cárcel que llaman perpetua o de la misericordia. Aunque en la confiscación de bienes y colores del hábito en algunas partes de la Corona de Aragón hay particulares fueros y privilegios y capítulos y costumbres que se deben guardar, poniendo el término del hábito y cárcel conforme a lo que el proceso resultare ${ }^{17}$. a llevar sambenito. Sin embargo, se produjo una absolución poco habitual. Jaime Policía, un francés acusado de luterano y sentenciado a muerte en la hoguera, "se convirtió la noche del auto y se admitió con cárcel y hábito irremisibles". Hubo que esperar al auto de fe del 8 de diciembre de 1572 para que los inquisidores volvieran a imponer sambenitos, pero tampoco como norma común. Solo sucedió con un francés, Pedro Cherú, que fue acusado de luterano, salió en el auto con su hábito de reconciliado, le dieron 200 azotes y fue condenado a hábito y cárcel perpetua irremisible. El criterio fue totalmente distinto dos años más tarde. En el auto de fe del 18 de abril de 1574 , se recurrió a la condena a hábito para la mayoría de los reconciliados por judaizantes o haber guardado la secta de Mahoma. En el caso de Isabel Díaz, morisca viuda vecina de Cañete fue testificada de que seguía orando a Mahoma y fue reconciliada con confiscación de bienes, hábito y cárcel por dos meses, y condenada también a 100 azotes "y que pasados los dos meses se le quite el hábito y se entregue a su amo en su lugar se le señale persona a quien acuda todos los domingos y fiestas para ser instruida". Como sucedió dos años antes, el sambenitillo también se utilizó para conmutar la pena de muerte, fue sólo al médico Juan de úbeda médico de 
64 años que ya había sido reconciliado en el auto de 1553 con hábito y cárcel perpetua por haber creído que no era venido el Mesías. En 1556 se lo habían quitado por provisión del Inquisidor General y se le permitió ejercer de médico, incluso curó a un inquisidor. Pero tuvo problemas con los ubetenses todopoderosos Diego de los Cobos y Juan Vázquez, por no haberles querido vender sus casas. Se le detuvo por haber negado que hubiese cometido delito y se le condenó a relajación. Al final se suspendió la condena a muerte porque "después se afirmó en las confesiones del proceso antiguo y hubo información que era melancólico". Los inquisidores prefirieron señalarle con el escapulario infamante y cárcel perpetua irremisible, además de 200 azotes. En el auto de fe de 1576 fueron condenados a sambenito todos los reconciliados por ceremonias de la secta de Mahoma, un total de 18. Sin embargo, en el auto de 10 de marzo de 1577 a casi ninguno de los 50 moriscos reconciliados les fue impuesto el escapulario, salvo a tres $^{22}$.

18 A la hora de obligar a portar el sambenitillo y cumplir cárcel perpetua, el criterio de los inquisidores de los distintos tribunales tampoco fue el mismo en el siglo XVII. En Sevilla, en el auto de fe de 1624 salieron 37 acusados de judaizar, de los cuales 36 fueron condenados a llevar sambenito y sólo a 7 se los quitaron al acabar la ceremonia y volver a la sede del tribunal. Además, se impuso el hábito a dos renegados. Uno de ellos, el pirata portugués Francisco Álvarez, fue condenado a azotes, hábito y tres años de cárcel perpetua para cumplirla en galeras sin el sambenito, que podía dejarlo "a la lengua del agua"23. Por esas mismas fechas, el 2 de diciembre de 1625, se celebró en la vecina Córdoba un auto de fe donde todos los reconciliados por judaizar (41) o islamizar (1) fueron condenados a hábito y cárcel, pero no todos con el mismo tiempo de reclusión: 3 a seis meses, 12 a un año, 15 a dos años y 12 a perpetua. El caso más singular fue el de Francisco Luque, preso por renegado, "sentenciado en 4 años de galeras y 200 azotes y que, después de haber cumplido las galeras al remo y sin sueldo, vuelva con el sambenito a tenerlo con cárcel perpetua en la de la Penitenciaría que tiene este Santo Oficio en esta ciudad" 24 .

En 1660 los inquisidores sevillanos no tuvieron el mismo criterio que sus antecesores en el cargo. Fue un auto de fe especialmente cruento con 90 judaizantes condenados, de los cuales 39 fueron mandados a la hoguera. Del resto de acusados por seguir la ley de Moisés únicamente 6 fueron sentenciados a llevar sambenito, de los cuales sólo uno tuvo que continuar con el sambenitillo, a los demás se los quitaron al acabar la ceremonia del auto ${ }^{25}$. A medida que los procesos inquisitoriales fueron en descenso, los condenados a portar el escapulario fueron muchos menos. Pero esta disminución y, por tanto, menor presencia en la calle no fue óbice para que los inquisidores continuaran recurriendo al estigma de esta ropa.

La imposición de los sambenitos también fue habitual en sentencias del siglo XVIII. En el auto particular, celebrado en Madrid el 22 de febrero de 1722 en la Iglesia de Santo Domingo, once reos sufrieron condenas (seis hombres y cinco mujeres, de entre 23 y 67 años) por judaizantes. Tuvieron distintas penas en función de la gravedad de sus delitos, fueron reconciliados, abjuraron, se les confiscaron sus bienes, y a todos se les impuso llevar hábito y cumplir cárcel perpetua ${ }^{26}$. En el auto celebrado en Córdoba en 1726 todos los reconciliados fueron condenados a llevar sambenito, en concreto 77 sentenciados por delitos de judaísmo. La última imposición que se conoce de sambenito en Córdoba fue en el auto de 5 de diciembre 1745. A Manuel Acuña, médico portugués vecino de Jaén, y a su esposa María García les obligaron a llevar hábitos durante su 
cárcel irremisible ${ }^{27}$. Una situación similar se produjo en el tribunal de Valladolid cuando se intensificó la persecución de los judaizantes. Durante el siglo XVIII fueron 715 los detenidos, las penas sobre los reconciliados (507, $71 \%$ de los procesados) fueron rigurosas con azotes, confiscación de bienes, sambenito y cárcel perpetua irremisible, además del envío a galeras que disminuye a partir de 1725. Aunque hubo continuidad en el recurso a los sambenitos como signos visibles de infamia, se observan también algunas muestras de benevolencia del tribunal respecto al cumplimiento de las sentencias. Así le sucedió a Narcisa Gutiérrez en 1746 que, después de estar tres años en la cárcel "ha venido el Consejo en dispensar a esta rea los diez meses y tiempo que le falta por cumplir su carcelería confinándola a lugar que os pareciese conveniente". Se supone que también se le permitió prescindir del sambenito como le ocurrió a Isabel Hernández, reconciliada en 1740 a hábito y cárcel perpetua, y en 1744 el Consejo ordenó "que a esta rea se le quite el sambenito y salga a cumplir destierro respecto de haber estado más de tres años en la cárcel de la penitencia de este tribunal”28.

\section{Entre el estigma y la distinción}

El sambenito, según Nicolau Eimeric, debía llevarse como signo de penitencia purificador: "dado que las cruces son la insignia del penitente, no debes rechazarla, sino amarla, porque el Señor Jesús llevó la cruz humildemente en sus hombros”. A este valor positivo, el discurso inquisitorial añadía la ejemplaridad: "llevar las cruces durante largo tiempo puede ser muy reparador, incluso muy meritorio porque la vergüenza que soportan los que la llevan puede ser bastante grande y servir mucho de ejemplo a los demás" ${ }^{29}$. Estos discursos inquisitoriales, conocidos por la mayoría de los ministros de la institución, tropezaban con la práctica y representación cotidianas de esta vestimenta.

Una de las primeras noticias que tenemos de un sambenitado es de 1501 por las calles de Soria: "cuando la Inquisición estaba en esa villa, se reconcilió Pedro de Madrid, ballestero [...], y que le mandaron traer una loba con una cruz delante y otra detrás, y que así la traía"30. La hopa o loba era el saco que llevaban los ajusticiados. El tribunal inquisitorial adaptó esta vestimenta pintando sendas cruces cristianas. El sambenito que se veía por la calle no tenía llamas, ni demonios, era un escapulario de color amarillento con dos cruces o aspas coloradas. Al día siguiente al auto de fe, los reconciliados eran trasladados a las casas de las cárceles de penitencia portando el sambenito, y también en estos espacios de reclusión debían llevarlo. Era, en palabras de Escamilla-Colin, "une prison ouverte sur une misère abyssale" ${ }^{31}$. Tenían que llevar el escapulario siempre encima si salían a la calle en busca de su sustento, a casa de sus familiares o para comprar o mendigar, bajo la supervisión del carcelero. Si cumplían condena en su casa, "haciendo su labor y hacienda", podían quitárselo cuando estuvieran solos, pero "si alguna persona la fuere a visitar o si se parare a la puerta de la calle de su casa, que se ponga el dicho sambenito"32. Algunas visitas podían provocar gestos contrarios a la norma, pero imprescindibles para el fin que se pretendía. En 1575 fue denunciado en Llerena, Rodrigo Salguero, ejecutor, por injurias al inquisidor Andrés de Álava, por decir que adivinaba el futuro y también por mantener relaciones con una penitenciada quitándole el sambenito: "Y se ha jactado y alabado que por muchas diversas veces había tenido cuenta carnal con una cierta penitenciada 
reconciliada y para ello le había quitado el hábito de sambenito que traía, echándolo por los rincones"33.

La cotidianidad de esta vestimenta por las calles era común durante el siglo XVI, y así lo percibió el artista flamenco Joris Hoefnagel en su viaje por España a mediados de esa centuria. Además de sus famosas vistas panorámicas de ciudades, pintó estampas de escenas cotidianas que le impactaron. Una de ellas fue la del "paciente sambenitado" de 1569. En ella dibujó un hombre barbado con el escapulario corto con una cruz de san Andrés hasta la cintura, sus manos entrecruzadas y un gesto de resignación. Hoefnagel añadió un comentario al pie en el que advertía sobre los peligros de la Inquisición para quienes viajaban por España, recomendándoles silencio, pasar inadvertidos y mucha paciencia a quienes tuvieran tratos con la Inquisición:

Meditad sobre mí, cuantos tenéis tratos con las tierras de España. Esto es la Inquisición. El Santo Oficio cuida así de quienes no dominan bien su lengua, persigue a muchos buenos hombres a quienes no les sirve de nada quejarse. Lleva el sambenito. Cierra la boca, cierra la bolsa. Este es el lema del mundo ${ }^{34}$.

En un lienzo de una vista de Sevilla de fines del siglo XVI, atribuido a Alonso Sánchez de Coello, se puede contemplar entre la multitud a una pareja de sambenitados. Caminan por el Arenal, después de haber atravesado el río por el Puente de Barcas, escoltados por alguaciles o familiares del Santo Oficio, seguramente porque habrían salido de la sede del tribunal en el Castillo de San Jorge y regresaban a su casa de reclusión ${ }^{35}$. El penitenciado en la calle era un apestado que podía ser señalado o insultado. La moral práctica recomendaba cierta mesura en ese trato vejatorio. En su tratado de casos morales, Fray Juan Enríquez intentó encontrar el equilibrio entre la injuria y el perdón:

Si la injuria que se hizo fue diciendo palabras afrentosas verdaderas y públicas, no hay obligación a desdecirse, sino a pedir perdón solamente. De manera que, aunque un hombre haya incurrido notoria y públicamente en cualquier infamia, siempre es pecado mortal decirle en su cara la infamia; pero, no será decirla en ausencia ${ }^{36}$.

Pero ¿qué sucedía si un individuo llevaba la marca de su pecado a la vista de todos? Para Enríquez, el caso más común era el sambenitado y para este ejemplo también proponía la misma condena y exención: "Y así si trayendo un hombre un sambenito puesto actualmente, le dijese otro en su cara Sambenitado, fuera de ser esto pecado mortal hay también obligación a pedirle perdón". La pena que debía imponerse al que insultaba era arbitraria, aunque quedaba exento de ella si pedía perdón sin necesidad de hacerlo en persona:

Pero debo advertir que no hay obligación de pedir perdón por su misma persona el que ha ofendido, sino que basta que lo haga por tercera persona, enviando a otro que le pida perdón en su nombre, y el ofendido siempre está obligado a perdonar, y si dijere que no quiere perdonar la injuria pecará mortalmente y el otro no está obligado a otra cosa más ${ }^{37}$.

Estos intentos casuistas para rebajar la animadversión que generaba el sambenitillo no alteraron la persistente percepción negativa que para muchos tenía. El rechazo podía llegar a extremos compulsivos, como el que manifestó Alonso Cano. Antonio Palomino recogió varios hechos protagonizados por el artista granadino que "ponía gran cuidado en que no le topase la ropa del ensambenitado a la suya; o bien pasándose a la otra acera, o metiéndose en un zaguán". Uno de los casos más llamativos sucedió cuando su ama, "que era nueva, y no sabía su humor llamó a uno de los hebreos penitenciados que pasaba por la calle para comprar un poco de lienzo". Cano entró de repente y se encontró con el sambenitado y "alborotó la casa a voces y por no tocar a él andaba 
buscando con qué darle para echarle fuera". Ama y condenado huyeron lo más rápido que pudieron, y la primera se escondió en casa de un vecino. Durante la cuarentena que tuvo que cumplir el ama, el artista investigó la limpieza de sangre de la mujer y hasta que no comprobó su pureza no la volvió a recibir. En este tiempo su escrúpulo le obligó

quitarse aquel calzado que tenía entonces, sin volvérselo a poner, por si acaso había pisado con ellos donde había puesto los pies el judío, y aún no paró aquí su tema, sino que mandó desempedrar y desenladrillar, y volverlo a poner de nuevo todo lo que discurría que el hebreo había pisado ${ }^{38}$.

Desde fines del XV, según Kamen, existió cierto paralelismo entre la institucionalización de los estatutos de limpieza de sangre y la imposición de la pena inquisitorial del sambenito. Incluso, cuando a fines del siglo XVI los estatutos de limpieza de sangre ya estaban en decadencia, este historiador ha insistido que la infamia era

el peor castigo que se podía imaginar en aquellos tiempos. En los tribunales penales ordinarios, los castigos que conllevaban vergüenza pública o ridículo eran más temidos que la propia sentencia a muerte, pues arruinaban la propia reputación en la comunidad para siempre, atrayendo el oprobio sobre la familia y los demás parientes ${ }^{39}$.

Recordemos que, por ejemplo, el inquisidor Juan Escobar del Corro en su Tractatus bipartitus de puritate et nobilitate probanda (1637) anteponía la muerte como mejor solución, antes que vivir toda la vida marcado por la infamia ${ }^{40}$.

Aunque los trataditas, en sus discursos sobre las bondades de la limpieza de sangre, construyeron una imagen correctiva sobre la ejemplaridad de la infamia, encontramos numerosas referencias en un sentido bien distinto. Marcos Fernández dedicó en su olla podrida (1655) un capítulo a boticarios y barberos e ironizó sobre su pasado judío con un comentario muy extendido: "con publicidad hacen del sambenito gala". Una expresión que utilizó de nuevo al tratar sobre la prostitución. En el capítulo VII titulado "De la gordura corrompida de esta ciudad en algún modo eterna" hizo esta expresiva descripción de la puerta, posiblemente, de una mancebía:

(...) advirtió un día, que otra mujer suya, que estaba sentada a la puerta, no con poco desenfado, haciendo del sambenito gala, tenía las rodillas demasiado separadas, los pececicos con justas fundas nevadas, llenando la vista el nácar de sus rosas, color o llama de fuego salía de sus ojos, señal que el horno estaba caliente, pues llamareaba o llamaba, no era su vez, y así la pasta o masa se horneó en el que le tocaba ${ }^{41}$.

Esa exhibición del sambenito sin muestras de resignación y de arrepentimiento también fue criticada por los moralistas cuando trataban en la profanidad en el vestir. El aragonés fray Jaime Barón, después de relacionar la penitencia de portar el sambenito con las pieles que cubrieron la desnudez de Adán y Eva antes de la expulsión, se preguntaba por los comportamientos tan favorables que algunos tenían respecto a la vestimenta inquisitorial:

¿Quién pues hace gala, quién vanidad y ostentación del sambenito? Solo un loco desatinado. Solo el que no tiene vergüenza ni honra delante de Dios y de los hombres. ¿Qué diríamos de un hombre o mujer que hacía gala y mostraba contento de que le vieran con el sambenito? ¿Qué hiciera mucho aprecio de que todos lo miraran y pusiera con atención en él los ojos? ¿Qué gastara, lo que para otras cosas le haría falta, para llevar un sambenito de tela rica y color salido, para que mejor lo vieran y repararan en él? Con razón se diría de tal hombre o mujer que era necio, que era loco, que era sumamente desvergonzado, pues hacía gala del señal, hábito o sambenito, protestativo de su pecado y culpas ${ }^{42}$. 
31 En sus preguntas, el dominico resumía muy bien como determinadas comunidades o individuos valoraban y utilizaban el sambenito como signo de distinción. El portugués Vicente da Costa en su Discurso contra los judíos (1631) dio todo tipo de detalles sobre el uso de esta prenda entre los judeoconversos portugueses y madrileños. El primer caso que le habían relatado fue el de un sambenitado que "todas las veces que salía fuera llamaba antes a dicha persona que era vecino suyo y le decía: venga vuestra merced y verá si voy gentil hombre". El segundo ejemplo era sobre un encuentro en Évora entre dos negociantes judíos (o, para ser más preciso, dos cristianos nuevos, uno de ellos acusado de judaizar): "fue visto que el penitenciado quitando[se] el sambenito le echó sobre los hombros del otro diciendo: téngale vuesa merced un poco y perderle ha el miedo". El converso condenado a llevar hábito protagonizó otro episodio que, para $\mathrm{Da}$ Costa, resumía muy bien el simbólico valor que esta comunidad daba a esa prenda:

Y de este mismo se sabe que teniendo después tienda de paños vino un hombre noble a comprarle ciertas varas para un vestido y no contentándose de algunos que le había mostrado diciendo que lo quería de más dinero, subió arriba y, trayendo un sambenito, dijo: Éste, señor, es el que más caro hay en casa porque me costó mucho ${ }^{43}$.

El sambenito era también un santo y seña para las familias conversas. Portarlo podía resultar un factor que asegurase el contacto antes que la incomunicación. Un suceso acaecido en el Hospital de Don Diego de Bálsamo en Toledo puso al descubierto uno de los medios que los presos utilizaban para tener contacto con el exterior. El converso Manuel Sarmiento, detenido en dicho hospital, se asomaba a una ventana para mantener correspondencia clandestina con sus correligionarios. Por el callejón pasaba un hombre condenado vestido de tela gris con su sambenito y contactaba con el detenido, que comentó a su compañero de celda: “iMira cómo se ríe! a través de él estoy en contacto con el exterior" ${ }^{44}$.

Da Costa también denunció como la condena a portar sambenitos no avergonzaba ni enmendaba a los judaizantes, antes "lo tienen tácitamente por honra". La solidaridad entre los conversos les permitía mostrar "falta de temor y demasiada largueza". Esta ayuda mutua la percibió en Madrid y en Portugal, con ejemplos como el de un sambenitado lisboeta “a quien muchos acudían pródigamente por el aprieto en que se vio, [y]decir en público esta misma verdad afirmando que todos eran unos y que si alguno dejaba de ser judío era por miedo o por vergüenza de lo que por ello se pasaba, más que ninguno era buen cristiano". Tales comportamientos demostraban, según da Costa, que la condena de cárcel perpetua y sambenito era insuficiente para corregir las prácticas judaizantes de tantos conversos. Su propuesta era imponer a los reconciliados otras penas más duras y sobre todo físicas:

Sean públicamente azotados y enviados a galeras como lo son personas de diferente calidad y que delinquen en diferentes pecados, siendo aquellos a las veces cristianos viejos y nobles, pues no parece justo que estos vayan más mal parados en pecados de menos calidad, y que los otros enemigos mortales de los sacramentos y de los fieles gente vil, baja y sin honra, antes esclavos, y con tantas presunciones de herejes, queden sin otro castigo el que le sirve de crédito con los demás (...) que estos hombres menos sienten seis sambenitos que cincuenta azotes ${ }^{45}$.

La condena a galeras era muy temida. Se conocen otros casos de algunos condenados a remar que prefirieron ser reconciliados antes que abjurar. Un ejemplo fue el de Francisco Sánchez del Barco que fue detenido en Cuenca por blasfemar y condenado a diez años de galeras y 200 azotes. Intentó evitar las galeras y para eso se declaró 
luterano. Procesado de nuevo en 1555, fue reconciliado en un auto de fe, le impusieron tres años de sambenito, cárcel y varias penitencias espirituales ${ }^{46}$.

\section{Los quitamientos}

Ante el estigma y la exclusión social, a los sambenitados se les ofrecía la posibilidad de librarse del castigo mediante una desigual negociación. Al margen de chantajes más o menos explícitos, era una práctica reconocida conmutar la pena de llevar hábito con el pago de composiciones. Para llevarlas a cabo estaban los muñidores de las habilitaciones particulares, individuos especializados en estas negociaciones. El autor de Artes de la Inquisición (1567), conocedor de estos mecanismos que suavizaban estas penas, expuso algunos de los medios con los que se podían quitar los hábitos infamantes:

La ocasión más frecuente de redimir este encarcelamiento y hábito de reo suele ser cuando el Rey hace donación a las doncellas o pajes del palacio, o a otros a quienes por ciertos gratuitos servicios determinó agraciar, de algunas redenciones de sambenitos; entonces el que recibe el don investiga diestramente en dónde y a quiénes se impuso aquella pena, y quién tiene mejores medios y voluntad de redimirla en más, para después pactar con ellos el precio, según puede mejor, en más o menos, teniendo en cuenta así la persona del que compra como también el mismo sambenito, pues los que eran irremisibles se suelen vender más caros; los anejos a cárcel perpetua más baratos; los que son por cierto tiempo y a voluntad de inquisidor a precio más bajo; y los que sólo son a voluntad del inquisidor aun a menos precio" ${ }^{47}$.

Todo se negociaba y los quitamientos fueron una de las fórmulas para que el Santo oficio consiguiera unos ingresos irregulares, pero siempre bien recibidos en su maltrecha hacienda. Ya a fines del siglo XV, el Santo Oficio recibía ingresos procedentes de la compra de la facultad de redimirse de la penitencia de llevar los sambenitos. ${ }^{48} \mathrm{En}$ 1498 se centralizaron en la Suprema las peticiones para los quitamientos: "Que, si no fuere los Inquisidores Generales, nadie pueda quitar sambenitos ni dar habilitaciones" ${ }^{49}$. Esta norma se comunicó de nuevo en 1513: "No pueden los inquisidores quitar sambenitos, ni alzar la carcelería, sin licencia del consejo por carta acordada" ${ }^{50}$. Y se tuvo que ir recordando año tras año "que si les pareciere usar de misericordia se le ponga tiempo a voluntad del Inquisidor General y no de los inquisidores" $"$.

En los tiempos de Adriano de Utrecht se procedió a transferir las competencias en esta materia a dos tribunales. El 28 de julio de 1520 a los inquisidores de Navarra se les cedió poder para conmutar y quitar seis sambenitos a las personas que les pareciere, imponiéndoles penitencias pecuniarias y espirituales "por usar con ellas misericordia y por otros buenos respectos que a ello nos mueve". Unos meses antes, el 8 de febrero de 1520, también se había dado comisión a los inquisidores de Sicilia para poder quitar y conmutar los sambenitos en otras penitencias saludables y pecuniarias a los que se habían ausentado del reino durante las revueltas de 1516 y 1517 contra las injerencias del poder real y del Santo Oficio sobre los poderes locales ${ }^{52}$. Las "segundas vísperas" habían culminado con el saqueo e incendio del palacio real y el asalto del tribunal inquisitorial, además de la eliminación de símbolos de la represión del Santo oficio, incluidos los sambenitos. El 21 de abril de 1522, Adriano de Utrecht, como Inquisidor 
General de Aragón, ordenó de nuevo reponer todos los símbolos como medida para restituir el poder de la Inquisición en Sicilia:

(...) hecha relación como al tiempo del tumulto y conmoción que en días pasados se siguió en esa ciudad de Palermo y en ese dicho reino, muchos que fueron reconciliados en ese santo oficio se quitaron los hábitos penitenciales o sambenitos que traían sobre sus personas, y a otros fueron quitados. Y que como quiere que se ha proveído que se volviesen a poner los dichos hábitos dice que hasta que no sea hecho y porque esto ha sido en gran deshonor de Dios y cargo de las conciencias de los que traían los dichos hábitos y no se los han vuelto. Por ende con la presente en virtud de santa obediencia mandamos a vos los dichos inquisidores y a cada uno de vos que luego proveáis que a todos los reconciliados en ese santo oficio que traigan los dichos hábitos penitenciales y se los quitaron y fueron quitados al tiempo de dicho tumulto y conmoción, se vuelvan los dichos hábitos y los traigan conforme a las sentencias contra ellos dadas so pena de impenitentes la cual ejecutaréis (o la haréis ejecutar conforme a derecho contra los que así no lo cumplieren).

En esa misma fecha, el Inquisidor General le envió una carta al virrey para que favoreciese "las cosas de la Inquisición y sus ministros en todo lo que se le ofreciere, como que se vuelvan a poner los sambenitos y los hábitos a los que se los habían quitado". Las órdenes no se cumplieron y, el 23 de febrero de 1523, el Inquisidor volvió a exigir a los inquisidores que obligasen a portar hábito a los sambenitados: "de que estamos maravillados y no es sin grande cargo de vuestras conciencias". Los ministros del Santo Oficio tenían que conseguir el cumplimiento de la orden, y para ese objeto les recomendaron que buscasen en "personas eclesiásticas y seglares que vos den todo el favor y ayuda que para esto fuere menester". El poder del Santo Oficio se había puesto en entredicho, y así se mantuvo durante los años sucesivos hasta 1529 en el que intensificó duramente la represión de los judaizantes ${ }^{53}$. En 1535, bajo el mandato de Alonso Manrique, el Santo Oficio retomó en parte el control de los quitamientos con una fórmula intermedia: "Que pasados tres años y no antes suele el Inquisidor General dispensar en hábito y cárcel perpetua y esto con parecer de los inquisidores y cuando se pone a voluntad del Inquisidor General podrá cuando quisiere". En 1540, con Pardo Tavera, se alentó a los sambenitados a solicitar la redención: "Que cumplido medio año de hábito y cárcel perpetua en que se votó, se avise al Consejo para que lo consulten con el Inquisidor General" ${ }^{54}$.

Los azotes y el sambenito eran la mayor vergüenza pública después de la sentencia, para el condenado, su familia y su comunidad. Una reacción muy significativa en defensa del honor de toda una familia la protagonizó Francisco de Borja en 1559, cuando su pariente Ana Enríquez, hija del marqués de Alcañices, fue condenada a llevar un sambenito por haber participado en los círculos luteranos de Valladolid. Borja consiguió que no se cumpliera la sentencia en ese punto ${ }^{55}$. La Inquisición utilizaba el sambenito como arma en las negociaciones con las víctimas, aquellas que colaboraban en las investigaciones solían ser redimidas de portarlo, aunque hubiesen sido condenadas a ello. A veces el quitar o no los hábitos se hacía según el criterio de los inquisidores de turno. A la granadina María Álvarez, pariente pobre de los Rojas, por ser la delatora de las prácticas judaizantes de esa familia, se le eximió en 1595 de esta infamia:

(...) sea admitida a reconciliación y que se le quite luego el hábito en acabándose de leer la sentencia en la cual se diga que ha sido buen confidente de sí y de otras personas y que fue la que dio mucha luz para todo lo que se ha descubierto así de su madre y hermanas y parientes. Es pobre ${ }^{56}$. 
colaboración. Jerónima de Cavedo y su hermana Magdalena fueron reconciliadas con sambenito "y que se le quitase luego" por haber sido buenas confidentes. Dos años más tarde se le quitó, después del auto, el hábito a Luisa Albornoz por haberse delatado y ser cristiana vieja. En 1660, a Juan Rodríguez Pinto sólo se impuso hábito por dos meses por ser confidente y, cuatro años después, a Simón Rodríguez Arias se le perdonó la infamia de llevar sambenito y la confiscación de bienes por haberse presentado de su voluntad a pedir misericordia y ser joven y buen confidente ${ }^{57}$. En 1661, la Suprema ya permitía que los prisioneros que no habían redimido pena de cárcel consiguiesen la dispensa del sambenito para salir a la compra diaria del pan $^{58}$.

41 En el asunto de la obligatoriedad del sambenito, el Santo oficio osciló constantemente entre la norma y la excepción. En febrero de 1640, el tribunal de Cartagena de Indias recibió una orden de la Suprema para que obligase a Juan Rodríguez Mesa a llevar el sambenito que se había quitado y le condenase a pagar quinientos ducados. Y unos meses más tarde, el tribunal americano recibía la revocación de la sentencia proveída contra Antonio Rodríguez Ferrerín, y se le ordenaba retirarle el sambenito y retornarle todos sus bienes, libros y papeles. No hubo una normativa clara o al menos que se cumpliera de manera rígida e incuestionada, de ahí que los tribunales recibieran reiterados envíos con lo dispuesto en los años de 1514 y 1600 sobre sambenitos y cárceles $^{59}$, o que desde Madrid se solicitase a las Inquisiciones de Lima, Cartagena de Indias y México, información sobre cómo habían procedido en la conmutación de los sambenitos a los reconciliados ${ }^{60}$.

Un caso ilustrativo del procedimiento que se seguía y de los intereses en juego con los quitamientos lo protagonizaron dos moriscos con el mismo nombre, Lorenzo Hernández, procesados por dos tribunales distintos y ambos condenados a llevar sambenito. En 1608, el tendero Lorenzo Hernández había conseguido que la Suprema le redimiese de llevar sambenito, fue entonces cuando lo sondeó un inquisidor de Llerena sobre cuánto estaba dispuesto pagar, y el morisco ofreció 60 ducados prestados por sus padres "ante su gran angustia". Ante esa respuesta, el Consejo pidió a los inquisidores de Llerena que investigasen si había más moriscos dispuestos a conmutar la pena de llevar sambenito. El resultado fue magnífico para la hacienda del Santo oficio: seis moriscos estaban dispuestos a pagar entre 150 reales y 60 ducados $^{61}$.

Por las mismas fechas, el homónimo morisco cordobés llevaba dos años presos en Córdoba y para sobrevivir hacía de factor, repartía papeles por los distintos despachos de la ciudad. Hacer ese trabajo con el sambenito le cerraba las puertas y despertaba muchas miradas de recelos y sospechas. Fue entonces cuando Lorenzo decidió quitarse el sambenito durante algunos momentos de su trabajo, con tan mala suerte que fue sorprendido dos veces e interrogado. Su respuesta fue que los oficiales municipales que le daban trabajo no querían que entrase en sus casas con el sambenito a la espalda. Lorenzo se quejó que le habían despedido, aunque todo el mundo sabía que esos oficiales eran conversos. Como sucedió con el morisco de Llerena, la Suprema decidió dispensarlo a cambio de una gratificación para los empleados del tribunal "hasta que termine la penitencia" ${ }^{62}$. Se trataba de financiar una ayuda de costa para viejos empleados de la Suprema. Los moriscos condenados, aunque arruinados ya por la confiscación de sus bienes, preferían endeudarse aún más antes que seguir llevando el sambenito. 


\section{Resistencias cotidianas}

La mácula cotidiana dio lugar a escrupulosos rechazos a los sambenitados y también a resistencias de éstos a portar dicha indumentaria. No todas las víctimas tenían la capacidad económica para afrontar los gastos que suponía la conmutación de la pena y el quitamiento del hábito y otras, aunque tuvieran el caudal suficiente, consideraban que ante la norma siempre cabía arriesgarse y transgredirla. En los primeros tiempos del Santo Oficio algunas víctimas intentaron, al menos, esconder el hábito. En 1511, la judaizante Inés López fue denunciada en Ciudad Real porque se "cubría el sambenito con las al(d)as del manto, ansí de la parte trasera como de delante"

Son numerosos los encausados por haber sido denunciados por no cumplir el castigo. Algunos exponían las razones por las que habían incumplido la norma, unos argumentos que, en ocasiones, buscaban la negociación. En 1659, en México fue condenado por no cumplir la obligación de llevar el sambenito Luis Pérez Roldán, que había sido reconciliado diez años antes por judaizante. El reo alegó que lo había hecho obligado por la necesidad: "dejaba el hábito de penitencia para ir a vender algunas madejas de pita o para ir a dar lección de armas a alguna persona, porque nadie le quería comprar ni tomar lección trayendo el hábito descubierto" ${ }^{64}$. Otros optaban por quitárselo, sobre todo si intentaban iniciar una nueva vida en un lugar distante de donde habían sido condenados. Ese fue el caso del mercader Simón Váezque, cuando por fin se embarcó en Campeche con destino a Sevilla y gracias a la ayuda económica del gobernador del puerto, se desprendió del sambenito ${ }^{65}$.

La resistencia femenina a portar el sambenito fue notoria en el Reino de Granada, quizás por el rechazo entre las moriscas a caminar obligatoriamente con una vestimenta doblemente cristiana, política y religiosa. En la visita de distrito que en 1577 hicieron los inquisidores a Baza encausaron de nuevo a tres mujeres reconciliadas que caminaban sin el sambenito. Una de ellas, la morisca Úrsula Mendoza, "traía el hábito de reconciliada cogido y debajo del brazo de manera que no se echaba de ver" ${ }^{66}$. También en Granada, en 1598 Inés Álvarez Herrera fue reconciliada por judaizante con hábito y cárcel perpetua. Solicitó al tribunal que le concediera la libertad y así se hizo por buena conducta. Pero en 1600 vuelve a ser detenida, esta vez por haberse quitado el hábito penitencial. Fue condenada a reclusión en su casa por dos meses y a otras penas espirituales. Paradójicamente, había transgredido la norma y había conseguido reducir la pena de hábito en diez meses ${ }^{67}$.

El rechazo en la calle a los sambenitados era particularmente intenso cuando éstos salían de la cárcel de penitencia a buscar su sustento. En 1512, la Inquisición permitió que los condenados a cárcel perpetua y hábito pudiesen salir a la calle a pedir limosna para mantenerse, siempre y cuando llevasen puesto su sambenito. Aquellos que les permitían cumplir la pena de cárcel en su casa eran doblemente beneficiados, puesto que podían recibir en su domicilio la ayuda de su familia o de los más allegados. No todos los tribunales tuvieron espacios carcelarios destinados al cumplimiento de la pena, de ahí la diversidad de comportamientos y de exhibición del sambenitado en el espacio público. Fue a comienzos del siglo XVII cuando el Santo Oficio comenzó a proyectar edificios para ser utilizados como cárceles de penitencia. De todos modos, la limitada financiación de los tribunales de distrito tenía como consecuencia una pésima atención a estos prisioneros de la fe. Hacia 1650 la situación en Granada era bastante deficiente y conflictiva. Los memoriales de presos y las protestas de uno de los 
miembros del tribunal ante este estado de cosas ofrecen un panorama bastante certero del rechazo a los sambenitados. El corregidor de la ciudad también se quejó al tribunal de las negativas consecuencias para el comercio que generaban las actividades de estos encarcelados:

(...) pues con andar estos hombres por las calles, y casas vendiendo, se les quita la mayor parte del comercio en sus tiendas, nadie va a ellas, pudiendo en su casa comprar y escoger, y con mayor comodidad de precios que estos hombres hacen: ellos se entienden, y no se pierden en el trato; antes vemos que saliendo casi desnudos de las cárceles secretas y, los más, confiscados sus bienes, se visten, se alhajan, y enriquecen con grandísima brevedad.

Según la memoria del fiscal del Santo Oficio, el doctor Crespos, los sambenitados salían de la reclusión a cualquier hora del día y sin limitación de tiempo alguna: "esto es literalmente la libertad... no padecen estrechura ni incomodidad de vivienda". Aunque reconocía que la cárcel era estrecha y "desacomodada", al vivir la mayor parte del tiempo en la calle, "su cárcel es toda Granada, los arrabales, los campos, las huertas, y todas las salidas de recreación, las casas, las de algunos vecinos a donde juegan y se entretienen". El punto central de su denuncia era el escándalo que producían en la ciudad y el descrédito de la autoridad del Santo oficio que propiciaba esta situación, de ahí que se lamentase: “¿De qué sirve, señor, llamarse cárcel, y cárcel de penitencia, o perpetua?"68.

\section{A modo de conclusión}

El impacto de la penitencia pública del sambenito callejero fue uno de los signos más útiles para la violencia simbólica del Santo oficio que marcaba al condenado y a su familia. No era un castigo leve, el que llevaba el sambenitillo quedaba expuesto al escarnio y al insulto cuando pasaba por las calles o cuando estaba en su trabajo. Multitud de gestos, persecuciones, burlas o insultos constataron de manera acumulativa la aplicación cotidiana de la pena por ser alguien inferior o diferente según la decisión de la Inquisición y de la cómplice o colaboradora comunidad de cristianos viejos.

50 La popularización de esta vestimenta y del término en el lenguaje coloquial confirmaría que el símbolo acabó absorbiendo el atributo, es decir, de ser un correctivo legal el sambenito se configuró como un correctivo cotidiano. No sólo cumplió la función de estigmatizar a unos determinados "otros", también normalizó la conducta cotidiana de extender acusaciones de menor entidad a propios y extraños, en casa o en la calle.

Es una opinión muy extendida que, más que la hoguera, lo que generaba pavor entre los procesados era ser marcado por la infamia de portar el sambenito, aunque fuera ésta una sanción menor y común entre los reconciliados. Pero no siempre sucedió así, hubo individuos o comunidades perseguidas que valoraron esa marca de un modo bien distinto. Hubo imposición y rechazo, aceptación y resistencia, normas y transgresiones, y siempre que fue posible para inquisidores y víctimas se buscó la negociación, una táctica de supervivencia tan común como cotidiana. 


\section{Fuentes}

\section{Fuentes inéditas}

AHN, Archivo Histórico Nacional, Madrid, España

Libros 317, 354, 355, 497, 498, 1228, 1231, 1234.

Legajos 80, 1952, 1953, 1972, 3365, 4475.

\section{Fuentes publicadas} Inquisición en el Obispado de Soria (1486-1502), Universidad Pontificia, Salamanca, 1985,8 volúmenes.

Barón, Fray Jaime, Remedio universal de todas las necesidades y trabajos, Luis de Cueto, Zaragoza, 1732, $564 \mathrm{p}$.

Beinart, Haim, Records of the Trials of the Spanish Inquisition in Ciudad Real, vol. III, The Israel National Academy of Sciences and Humanities, Jerusalén, 1977, 4 volúmenes.

Carena, César, Tractatus de Officio Sanctissima Inquisitionis, J. Montii, Bolonia, 1668.

Carrete Parrondo, Carlos, Fontes Iudaeroum Regni Castellae, vol. II, "El Tribunal de la Da Costa, Vicente, Discurso contra los judíos, Antonia Ramírez, Salamanca, 1631, 237 p.

Eimeric, Nicolau, Directorium Inquisitorum, Antonium Zalterium, Venecia, 1607, 931 p.

Enríquez, Fray Juan, Questiones prácticas de casos morales, Bernardo Nogués, Valencia, 1647, 204 p.

Fernández, Marcos, Olla podrida a la española, Felipe Van Eyck, Amberes, 1655, 324 p.

García Fuentes, José María, Visitas de la Inquisición al Reino de Granada, Universidad de Granada, Granada, 2006, 450 p.

González Montano, Reinaldo, Artes de la Inquisición española [1567], Almuzara, Córdoba, 2010, 249 p.

Gracia Boix, Rafael, Autos de Fe y Causas de la Inquisición de Córdoba, Diputación de Córdoba, Córdoba, 1983, 687 p.

Jiménez Monteserín, Miguel, Introducción a la Inquisición Española. Documentos básicos para el estudio del Santo Oficio, Editora Nacional, Madrid, 1980, 845 p.

Palomino, Antonio, El museo pictórico y escala óptica [1724], Imprenta de Sancha, Madrid, 1795, 3 volúmenes.

6 Relación de los reos que salieron en el Auto Particular Fe, 22 de febrero de 1722, Joseph Serrete, Madrid, 1722, $8 \mathrm{p}$.

Yepes, Fray Antonio de, Coronica general de la orden de San Benito, Matías Mares, Pamplona, 1613, 458 p. 


\section{BIBLIOGRAFÍA}

Alberro, Solange, Inquisición y sociedad en México, 1571-1700, Fondo de Cultura Económica, México, 1988, $623 \mathrm{p}$.

Bennassar, Bartolomé, Inquisición española: poder político y control social, Crítica, Barcelona, 1981, $347 \mathrm{p}$.

Bouza, Fernando, De Mercator a Blaeu. España y la Edad de Oro de la cartografía en las diecisiete provincias de los Países Bajos, Nerea, Madrid, 1995, 172 p.

Caro Baroja, Julio, Los judíos en la España Moderna y Contemporánea, Istmo, Madrid, 2000, 3 tomos.

Chamorro, José María, “Vida y costumbres de los judeoconversos, según los procesos inquisitoriales”, Revista de Dialectología y Tradiciones Populares, Madrid, vol. 48, n², 1993, p. 57-84.

Contreras, Jaime, Historia de la Inquisición Española (1478-1834): herejías, delitos y representación, Arco Libros, Madrid, 1997, 80 p.

Dedieu, Jean-Pierre, L'administration de la foi. L'Inquisition de Tolède (XVI-XVIII siècle), Casa de Velázquez, Madrid, 1992, 406 p.

Del Ama, José Carlos, "La fachada del poder. El sambenito como nexo entre pueblo e instituciones”, en Apolinário, António \& Usunáriz, Jesús María (eds.), Poderes y autoridades en el Siglo de Oro: Realidad y representación, Eunsa, Pamplona, 2012, p. 17-29.

Escamilla-Colin, Michèle, Crimes et chatiments dans l'Espagne inquisitoriale. Essai de typologie délictive et punitive sous le dernier Habsbourg et le premier Bourbon, Berg International, París, 1992, 2 volúmenes.

Fernández García, María Ángeles, Inquisición, comportamiento y mentalidad en el Reino de Granada (1600-1700), Universidad de Granada, Granada, 1989, 402 p.

Gacto, Enrique, “Aproximación al derecho penal de la Inquisición”, en Escudero, José Antonio, Perfiles jurídicos de la Inquisición española, Universidad Complutense de Madrid, Madrid, 1986, p. 175-194.

García Cárcel, Ricardo, Orígenes de la Inquisición española. El Tribunal de Valencia, 1478-1530, Península, Barcelona, 1976, 306 p.

García Ivars, Flora, La represión en el tribunal inquisitorial de Granada 1550-1819, Akal, Madrid, 1991, $301 \mathrm{p}$.

García-Molina, Antonio M., El régimen de penas y penitencias en el tribunal de la Inquisición de México, UNAM, México, 1999, 679 p.

Goffman, Erving, Estigma. La identidad deteriorada, Amorrortu, Buenos Aires, 2008, 183 p.

Gómez, Francisco Javier, Logroño histórico [1893], I. E. R. / Ayuntamiento de Logroño, Logroño, $1998,735 \mathrm{p}$.

Hernández Franco, Juan, Sangre limpia, sangre española. El debate de los estatutos de limpieza de sangre (siglos XV-XVII), Cátedra, Madrid, 2011, 300 p.

Jiménez Gascón, Zoraida, Propaganda e Inquisición en la Sevilla del siglo XVII. El auto de fe general como espectáculo propagandístico en decadencia, Tesis de doctorado en periodismo, Universidad de Sevilla, Sevilla, España, 2015, 758 p. 
Jiménez Monteserín, Miguel, Triunfo de la Católica Religión. El auto de Fe de Cuenca de 1654, Diputación Provincial, Cuenca, 2010, 608 p.

Kamen, Henry, La Inquisición española. Una revisión histórica, Crítica, Barcelona, 1999, 443 p.

Lavenia, Vicenzo, L'infamia e il perdono. Tributi, pene e confessione nella teologia morale della prima età moderna, Il Mulino, Bolonia, 2004, 407 p.

Llorente, Juan Antonio, Historia de la Inquisición en España, Tomo I, Hiperión, Madrid, 1980, 332 p.

Pérez, Joseph, Crónica de la Inquisición en España, Martínez Roca, Barcelona, 2002, 508 p.

Prado, Ángel de, Las hogueras de la intolerancia. La actividad represora del Tribunal Inquisitorial de Valladolid, Junta de Castilla y León, Valladolid, 1996, 252 p.

Rivero, Manuel, "La Inquisición española en Sicilia”, en Pérez Villanueva, Joaquín \& Escandell, Bartolomé (dirs.), Historia de la Inquisición en España y América, vol. 3, “Temas y problemas", Biblioteca de Autores Cristianos, Madrid, 2000, p. 1031-1222.

Sánchez Ortega, María Helena, "La situación de los presos en las cárceles del Santo Oficio de Granada durante el siglo XVII", Espacio, tiempo y forma. Revista de la Facultad de Geografía e Historia, Madrid, n4, 1989, p. 669-684.

Thomas, Werner, Los protestantes y la Inquisición en España en tiempos de Reforma y Contrarreforma, Leuven University Press, Lovaina, 2001, 714 p.

Trasselli, Carmelo, Da Ferdinando il Cattolico a Carlo V. L'esperienza siciliana, 1475-1325, vol. II, Rubettino Editore, Soveria Mannelli, 1982, 820 p.

\section{NOTAS}

1. Cfr. Jiménez Monteserín, Miguel, Triunfo de la Católica Religión. El auto de Fe de Cuenca de 1654, Diputación Provincial, Cuenca, 2010, p. 68.

2. Bennassar, Bartolomé, Inquisición española: poder político y control social, Crítica, Barcelona, 1981, p. 117-118. Sobre la construcción intelectual de la infamia y las protestas ante las reglas inquisitoriales véase Lavenia, Vicenzo, L'infamia e il perdono. Tributi, pene e confessione nella teologia morale della prima età moderna, Bolonia, Il Mulino, 2004, p. 147-156.

3. Contreras, Jaime, Historia de la Inquisición Española (1478-1834), Arco Libros, Madrid, 1997, p. 60.

4. Contreras, Jaime, Historia de la Inquisición, Op. Cit., p. 60.

5. Sobre el carácter propagandístico de los sambenitos véase Gacto, Enrique, "Aproximación al derecho penal de la Inquisición", en Escudero, José Antonio, Perfiles jurídicos de la Inquisición española, Universidad Complutense de Madrid, Madrid, 1986, p. 185-188.

6. Archivo Histórico Nacional de España (AHN), Inquisición, libro (lib.) 497 f. 55 r.

7. Del Ama, José Carlos, "La fachada del poder. El sambenito como nexo entre pueblo e instituciones”, en Apolinário, António \& Usunáriz, Jesús María (eds.), Poderes y autoridades en el Siglo de Oro: Realidad y representación, Eunsa, Pamplona, 2012, p. 17-29.

8. Goffman, Erving, Estigma. La identidad deteriorada, Amorrortu, Buenos Aires, 2009.

9. Del Ama, J. C., "La fachada del poder". Op. Cit., p. 25-27.

10. Thomas, Werner, Los protestantes y la Inquisición en España en tiempos de Reforma y Contrarreforma, Leuven University Press, Lovaina, 2001, p. 51-104.

11. Thomas, W., Los protestantes y la Inquisición, Op. Cit., p. 68.

12. Thomas, W., Los protestantes y la Inquisición, Op. Cit., p. 68.

13. Yepes, Fray Antonio de, Coronica general de la orden de San Benito, Matías Mares, Pamplona, 1613, Tomo II, cent. II, ff. 336-339. 
14. Yepes, Fray Antonio de, Coronica general de la orden de San Benito, Matías Mares, Pamplona, 1613, Tomo II, cent. II, ff. 336-339.

15. AHN, Inquisición, legajo (leg.) 4475 expediente (exp.) 4. El subrayado es nuestro. Resulta extraño que Juan Antonio Llorente no aludiera a los sambenitillos entre los tipos de hábitos que describió en su Historia crítica (publicada en 1817), aunque reconoce que "fueron fecundísimas las imaginaciones de los inquisidores para multiplicar tantas especies de sambenito como clases de reos condenados". Llorente, Juan Antonio, Historia de la Inquisición en España, Tomo I, Hiperión, Madrid, 1980, p. 249-250.

16. Carena, César, Tractatus de Officio Sanctissima Inquisitionis, J. Montii, Bolonia, 1668, parte III, título 14, no84 y 85. Sobre el hábito de penitencia, p. 319.

17. Jiménez Monteserín, Miguel, Introducción a la Inquisición Española. Documentos básicos para el estudio del Santo Oficio, Editora Nacional, Madrid, 1980, p. 219.

18. AHN, Inquisición, lib. 1228, f. 250 y lib. 1231, f. 114 [107].

19. AHN, Inquisición, lib. 1234, f. 421v.

20. Contreras, J., La Inquisición, Op. Cit., p. 60.

21. Gómez, Francisco Javier, Logroño histórico [1893], IER, Logroño, 1998, p. 624-627. Citado también en Caro Baroja, Julio, Los judíos en la España Moderna y Contemporánea, Tomo I, Istmo, Madrid, 2000, p. 348.

22. Todas las citas de este párrafo se encuentran en la recopilación documental de Gracia Boix, Rafael, Autos de Fe y Causas de la Inquisición de Córdoba, Diputación de Córdoba, Córdoba, 1983, p. 85-86, 123 y 146-147.

23. Jiménez Gascón, Zoraida, Propaganda e Inquisición en la Sevilla del siglo XVII. El auto de fe general como espectáculo propagandístico en decadencia, Tesis de doctorado en periodismo, Universidad de Sevilla, Sevilla, España, 2015, p. 376.

24. Gracia Boix, R., Autos de Fe, Op. Cit., p. 386-390.

25. Jiménez Gascón, Z., Propaganda e Inquisición, Op. Cit, p. 457 y ss.

26. Relación de los reos que salieron en el Auto Particular Fe, 22 de febrero de 1722, Joseph Serrete, Madrid, 1722, f. 2619.

27. Gracia Boix, R., Autos de Fe, Op. Cit., p. 519-530.

28. Prado, Ángel de, Las hogueras de la intolerancia. La actividad represora del Tribunal Inquisitorial de Valladolid, Junta de Castilla y León, Valladolid, 1996, p. 90 y 108.

29. Eimeric, Nicolau, Directorium Inquisitorum, Tomo III, Antonium Zalterium, Venecia, 1607, p. 506-507.

30. Carrete Parrondo, Carlos, Fontes Iudaeroum Regni Castellae, Tomo II, "El Tribunal de la Inquisición en el Obispado de Soria (1486-1502)", Universidad Pontificia, Salamanca, 1985, doc. 298, año 1501, p. 128, línea 4. Véase también Chamorro, José María, "Vida y costumbres de los judeoconversos, según los procesos inquisitoriales”, Revista de Dialectología y Tradiciones Populares, Madrid, vol. 48, n², 1993, p. 60.

31. Escamilla-Colin, Michèle, Crimes et chatiments dans l'Espagne inquisitoriale. Essai de typologie délictive et punitive sous le dernier Habsbourg et le premier Bourbon, Tomo I, Berg International, París, 1992, p. 792.

32. Citado en Pérez, Joseph, Crónica de la Inquisición en España, Martínez Roca, Barcelona, 2002, p. 352.

33. AHN, Inquisición, leg. 1972 exp. 12.

34. Hoefnagel, Joris, "Patientighen Sanbenittado", Traité de la patience, Bibliothèque Municipale de Rouen, Collection Leber. Véase el comentario de Fernando Bouza a este dibujo en De Mercator a Blaeu. España y la Edad de Oro de la cartografía en las diecisiete provincias de los Países Bajos, Nerea, Madrid, 1995, p. 142-143.

35. Óleo sobre lienzo (146 x 295 cm), Museo de América de Madrid (España). 
36. Enríquez, Fray Juan, Questiones prácticas de casos morales, Bernardo Nogués, Valencia, 1647, f. 36.

37. Enríquez, Fray Juan, Questiones prácticas de casos morales, Bernardo Nogués, Valencia, 1647, f. 36.

38. Palomino, Antonio, El museo pictórico y escala óptica [1724], Tomo II, Imprenta de Sancha, Madrid, 1795, p. 585-586.

39. Kamen, Henry, La Inquisición española. Una revisión histórica, Crítica, Barcelona, 1999, p. 223 y 236.

40. Hernández Franco, Juan, Sangre limpia, sangre española. El debate de los estatutos de limpieza de sangre (siglos XV-XVII), Cátedra, Madrid, 2011, p. 136.

41. Fernández, Marcos, Olla podrida a la española, Felipe Van Eyck, Amberes, 1655, p. 133 y 199.

42. Barón, Fray Jaime, Remedio universal de todas las necesidades y trabajos, Tomo I, Luis de Cueto, Zaragoza, 1732, p. 223.

43. Da Costa, Vicente, Discurso contra los judíos, Antonia Ramírez, Salamanca, 1631, p. 134-135.

44. AHN, Inquisición, leg. 80, exp.4 (1662), véase Escamilla, M., Crimes, Op. Cit, p. 798.

45. Da Costa, V., Discurso, Op. Cit., p. 138, 158 y 225.

46. Cit. Thomas, W., Los protestantes, Op. Cit., p. 26-28.

47. González Montano, Reinaldo, Artes de la Inquisición española, Almuzara, Córdoba, 2010, p. 113.

48. Dedieu, Jean-Pierre, L'administration de la foi. L'Inquisition de Tolède (XVI-XVIII siècle), Casa de Velázquez, Madrid, 1992, p. 269. Se conocen también algunas series de ingresos en el tribunal de Valencia por quitamiento de hábitos o "gramalletes". Desde 1515 a 1518 los ingresos por la compra de la facultad de redimirse de esta penitencia fueron los siguientes: 1515-7.461 sueldos; 1516-841 sueldos; 1518-9.661 sueldos". Véase García Cárcel, Ricardo, Orígenes de la Inquisición española. El Tribunal de Valencia, 1478-1530, Península, Barcelona, 1976, p. 144.

49. AHN, Inquisición, lib. 1231, f. 119r.

50. AHN, Inquisición, lib. 1228, f. 250.

51. Cuenca, 9 de enero y Madrid, 30 de octubre 1516. AHN, Inquisición, lib. 1231, f. 103.

52. Sobre las revueltas en diversas localidades de Sicilia, en 1516-1517, Trasselli, Carmelo, Da Ferdinando il Cattolico a Carlo V. L'esperienza siciliana, 1475-1325, vol. II, Rubettino Editore, Soveria Mannelli, 1982, p. 585-722. Véase también Rivero, Manuel, “La Inquisición española en Sicilia, en Pérez Villanueva, Joaquín \& Escandell, Bartolomé (dirs.), Historia de la Inquisición en España y América, vol. 3, "Temas y problemas", Biblioteca de Autores Cristianos, Madrid, 2000, p. 1042-1043.

53. AHN, Inquisición, lib. 317, ff. 16v, 65 v, 315-316v y 381.

54. AHN, Inquisición, lib. 1231, ff. 114-115.

55. Kamen, H., La Inquisición, Op. Cit., p. 236.

56. AHN, Inquisición, leg. 1953 exp. 28, cit. García Ivars, Flora, La represión en el tribunal inquisitorial de Granada 1550-1819, Akal, Madrid, 1991, p. 231.

57. AHN, Inquisición, leg. 1953, exp. 21, n²2 (1606) y exp. 54 (1608); leg. 1952, exp. 4 (1660 y 1664). Véase también Fernández García, María Ángeles, Inquisición, comportamiento y mentalidad en el Reino de Granada (1600-1700), Universidad de Granada, Granada, 1989, p.103 y 166.

58. AHN, Inquisición, lib. 498, f. 160r.

59. AHN, Inquisición, lib. 354, ff. 149r-150v; 157v-158v; y 324v-325v.

60. AHN, Inquisición, lib. 355, ff. 303v- 308v.

61. AHN, Inquisición, leg. 3365, exp. 1. Escamilla-Colin calcula que el pago de estos moriscos correspondía entre 6 semanas y 6 meses del salario de un jornalero (Crimes, Op. cit., p. 812).

62. AHN, Inquisición, leg. 1952, exp. 16.

63. Beinart, Haim, Records of the Trials of the Spanish Inquisition in Ciudad Real, vol. II, The Israel National Academy of Sciences and Humanities, Jerusalén, 1977, p. 97. 
64. Citado en García-Molina, Antonio M., El régimen de penas y penitencias en el tribunal de la Inquisición de México, UNAM, México, 1999, p. 540, n. 113.

65. Citado en Solange Alberro, Inquisición y sociedad en México, 1571-1700, Fondo de Cultura Económica, México, 1988, p. 502.

66. Citado en García Fuentes, José María, Visitas de la Inquisición al Reino de Granada, Universidad de Granada, Granada, 2006, p. 186.

67. AHN, Inquisición, leg. 1953, exp. 28. Véase García Ivars, F., La represión en el tribunal inquisitorial, Op. Cit., p. 230.

68. Sánchez Ortega, María Helena, "La situación de los presos en las cárceles del Santo Oficio de Granada durante el siglo XVII", Espacio, Tiempo y Forma. Revista de la Facultad de Geografía e Historia, Madrid, n4, 1989, p. 669-684.

\section{RESÚMENES}

El impacto de la penitencia pública del sambenitillo o sambenito callejero fue uno de los signos más útiles para la violencia simbólica que marcaba al condenado y a su familia, y que tanto implementaron los tribunales inquisitoriales en el Mundo Hispánico. No era un castigo leve, el que lo llevaba quedaba expuesto al escarnio y al insulto cuando pasaba por las calles o cuando estaba en su trabajo. Esta vestimenta ignominiosa marcó la memoria colectiva hasta convertirse en un término de uso coloquial en nuestra lengua para referirse al descrédito de un individuo. La tratadística y las fuentes inquisitoriales recogen numerosas noticias sobre los usos y penitencia pública que se imponían y sufrían con estas prendas.

The impact of the public penance of the sambenitillo or street sambenito was one of the most useful signs for the symbolic violence that marked the convicted man and his family, and that both inquisitorial courts implemented in the Hispanic World. It was not a light punishment, the one who carried it was exposed to scorn and insult when he passed through the streets or when he was at work. This ignominious clothing marked collective memory until it became a term of colloquial use in our language to refer to the discredit of an individual. The treatises and inquisitorial sources collect numerous news about the uses and public penance that were imposed and suffered with these garments.

L'impact de la pénitence publique du sambenitillo ou sambenito de rue a été l'un des signes les plus utiles de la violence symbolique qui a marqué le condamné et sa famille, et qui a été ainsi mise en œuvre par les tribunaux inquisitoriaux dans le monde hispanique. Ce n'était pas une punition légère, celui qui la portait était exposé au mépris et à l'insulte lorsqu'il passait dans la rue ou lorsqu'il était au travail. Cette tenue ignominieuse a marqué la mémoire collective jusqu'à ce qu'elle devienne un terme familier dans notre langue pour désigner le discrédit d'un individu. Les sources inquisitoriales et la presse font état de nombreux rapports sur les utilisations et la pénitence publique imposées et subies par ces vêtements. 
ÍNDICE

Palabras claves: inquisición, cárcel, mundo hispánico, negociación, transgresión

Mots-clés: inquisition, prison, monde hispanique, négociation, transgression

Keywords: inquisition, prison, hispanic world, negotiation, transgression

\section{AUTOR}

\section{MANUEL PEÑA DÍAZ}

Doctor en Historia, Universitat Autònoma de Barcelona. Catedrático de Historia Moderna, Universidad de Córdoba, España.

mpdiaz@uco.es

Este artículo forma parte del proyecto Herejía y sociedad en el mundo hispánico de la edad moderna: Inquisición, imagen y poder (PGC2018-094899-B-C53) financiado por el Ministerio de Ciencia, Innovación y Universidades del Gobierno de España 